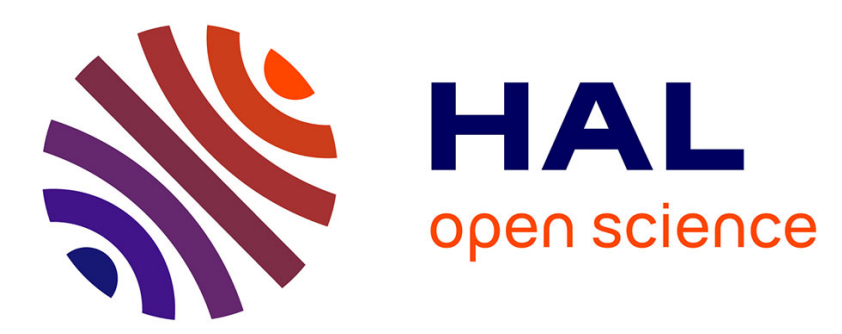

\title{
Half-sandwich molybdenum(III) compounds containing diazadiene ligands and their use in the controlled radical polymerization of styrene
}

François Stoffelbach, Rinaldo Poli, Philippe Richard

\section{- To cite this version:}

François Stoffelbach, Rinaldo Poli, Philippe Richard. Half-sandwich molybdenum(III) compounds containing diazadiene ligands and their use in the controlled radical polymerization of styrene. Journal of Organometallic Chemistry, 2002, 663 (1-2), pp.269-276. 10.1016/S0022-328X(02)01878-8 . hal03283779

\section{HAL Id: hal-03283779 \\ https://hal.science/hal-03283779}

Submitted on 19 Jul 2021

HAL is a multi-disciplinary open access archive for the deposit and dissemination of scientific research documents, whether they are published or not. The documents may come from teaching and research institutions in France or abroad, or from public or private research centers.
L'archive ouverte pluridisciplinaire HAL, est destinée au dépôt et à la diffusion de documents scientifiques de niveau recherche, publiés ou non, émanant des établissements d'enseignement et de recherche français ou étrangers, des laboratoires publics ou privés. 


\section{Half-sandwich Molybdenum(III) Compounds Containing Diazadiene}

\section{Ligands and Their Use in the Controlled Radical Polymerization of}

\section{Styrene $^{\dagger}$}

François Stoffelbach, Rinaldo Poli* and Philippe Richard

Laboratoire de Synthèse et d'Electrosynthèse Organométalliques, Université de Bourgogne,

Faculté de Science Gabriel, 6 boulevard Gabriel, 21000 Dijon, France

Proofs to :

Prof. Rinaldo Poli

Tel +33-(0)380396881

Fax +33-(0)380393720

poli@u-bourgogne.fr

${ }^{\dagger}$ Dedicated to Pascual Royo on the occasion of his $65^{\text {th }}$ birthday 


\section{Pictogram for the graphical table of contents}

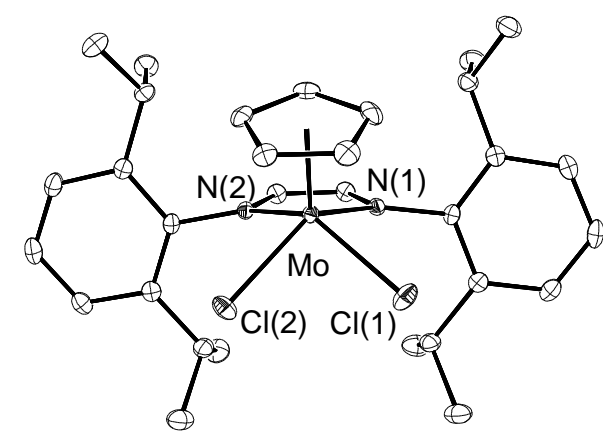

\section{Synopsis}

A few members of the $\mathrm{CpMoCl}_{2}(\mathrm{dad})(\mathrm{dad}=\mathrm{RN}=\mathrm{CH}-\mathrm{CH}=\mathrm{NR})$ family have been synthesized and characterized by analytical, spectroscopic, and electrochemical methods, including an Xray structure for the $\mathrm{R}=\mathrm{C}_{6} \mathrm{H}_{3} \operatorname{Pr}_{2}{ }_{2}-2,6$ member. They are capable of controlling the radical polymerization of styrene by both ATRP and SFRP mechanisms simultaneously. 


\section{Abstract}

The reaction of $\mathrm{CpMoCl}_{2}$ with diazadiene ligands $\mathrm{RN}=\mathrm{CH}-\mathrm{CH}=\mathrm{NR}\left(\mathrm{R}_{2}\right.$-dad $)$ affords the corresponding paramagnetic complexes $\mathrm{CpMoCl}_{2}\left(\mathrm{R}_{2}\right.$-dad $)\left(\mathrm{R}=\mathrm{Ph}, \mathbf{1} ; p\right.$-Tol, $2 ; \mathrm{C}_{6} \mathrm{H}_{3} \mathrm{Pr}_{2}^{\mathrm{i}}-2,6$, 3; and $\left.\operatorname{Pr}^{\mathrm{i}}, 4\right)$. All compounds have been characterized by EPR spectroscopy and have been investigated by cyclic voltammetry. They display one-electron oxidation and reduction processes, these being reversible or irreversible depending on the nature of $\mathrm{R}$. The irreversibility of the reduction wave is due to a chemical follow-up process which consists of chloride loss from the reduced product. This phenomenon is suppressed ion the presence of excess chloride in solution. An X-ray structure of $\mathbf{3}$ verifies the mononuclear natureof the compound and the chelating mode of the dad ligand, the $\mathrm{MoN}_{2} \mathrm{C}_{2}$ ring being essentially planar. The N-C and C-C bond distance pattern suggests the important contribution of an enediamido $\mathrm{Mo}(\mathrm{V})$ limiting form. In the presence of 1-bromoethylbenzene, complexes 1-4 catalyze the controlled/"living" radical polymerization of styrene. Complex $\mathbf{3}$ also leads to a controlled/"living" radical polymerization of styrene in the presence of AIBN as a radical generator. Therefore, this is the second example of a compound which is capable of controlling the styrene radical polymerization under both ATRP and SFRP conditions.

\section{Keywords}

Molybdenum, cyclopentadienyl, diazadiene ligands, paramagnetic organometallics, controlled radical polymerization 


\section{Introduction}

Half-sandwich complexes of Mo(III) having a four-legged piano stool structure and a 17-electron configuration now represent a relatively large family of stable organometallic radicals [1]. Their susceptibility to be oxidized to 16-electron (generally spin triplet) Mo(IV) derivatives or else to be reduced to saturated Mo(II) derivatives depends very strongly on the electronic properties of the ligands. Nevertheless, this family of compounds has been found to be compatible with a broad spectrum of ancillary ligands, from the very $\pi$-acidic $\mathrm{CO}$, as in $\left[\mathrm{Cp}^{*} \mathrm{MoCl}\left(\mathrm{PMe}_{3}\right)_{2}(\mathrm{CO})\right]^{+}[2]$, to the very $\pi$-basic $\mathrm{OH}$, as in $\left[\mathrm{CpMo}(\mathrm{OH})\left(\mathrm{PMe}_{3}\right)_{3}\right]^{+}[3]$, through the $\pi$-neutral alkyls, as in $\mathrm{CpMo}\left(\mathrm{CH}_{3}\right)_{2}\left(\mathrm{PMe}_{3}\right)_{2}$ [4]. The dichloride family, $\mathrm{CpMoCl}_{2} \mathrm{~L}_{2}$, includes members where $\mathrm{L}$ or $\mathrm{L}_{2}=$ tertiary phosphine [5], phosphine donors linked as side chains to the cyclopentadienyl ligand [6], or dienes [7]. Members containing bifunctional ligands such as phosphine-oxazoline, phosphine-amide or phosphine-thioether [8, 9], have also been reported more recently, these being the first examples featuring neutral $\mathrm{N}$, $\mathrm{O}$ or $\mathrm{S}$ donors. We have been unable for some time to extend this family to ligands $\mathrm{L}_{2}$ with two hard nitrogen donors. We report here the first examples of this class, obtained using a variety of 1,4 -diazadienes, $\mathrm{RN}=\mathrm{CH}-\mathrm{CH}=\mathrm{NR}$. Diazadienes have previously shown their coordinating ability in the related half-sandwich $\mathrm{Cp}^{*} \mathrm{MCl}_{2}(\mathrm{RN}=\mathrm{CH}-\mathrm{CH}=\mathrm{NR})(\mathrm{M}=\mathrm{Nb}, \mathrm{Ta})$ families [10-14].

A further interest of this work is related to our recent discovery [15] that complexes $\mathrm{CpMoCl}_{2}\left(\mathrm{PMe}_{3}\right)_{2}$ and $\mathrm{CpMoCl}_{2}(\mathrm{dppe})$ are able to control the radical polymerization of styrene by two different mechanisms simultaneously, i.e. Atom Transfer Radical Polymerization (ATRP) and Stable Free Radical Polymerization (SFRP) (Scheme 1), an unprecedented phenomenon. Both these equilibria have the property of equilibrating the reactive radical $(\mathrm{R})$ with a dormant species (M-R for SFRP, X-R for ATRP), thereby lowering the free radical concentration and consequently suppressing the bimolecular 
termination processes. Other families of metal complexes such as $\mathrm{CuX}\left(\mathrm{L}_{3}\right)\left(\mathrm{X}=\mathrm{Cl}\right.$ or $\mathrm{Br}$; $\mathrm{L}_{3}$ $=$ triamine, diaminopyridine, etc.) or $\mathrm{CpRuCl}_{2}\left(\mathrm{PPh}_{3}\right)$ have been shown to be capable of controlling radical polymerization by the ATRP mechanism only (see Scheme 1) [16], while yet other families (organocobalt porphyrin complexes, for instance [17]) can only operate by the SFRP mechanism. Yet another novel feature of the half-sandwich Mo(III) complexes is the transition from "living" to catalyzed chain transfer (CCT) by a simple modification of the coordination sphere. While the two phosphine complexes mentioned above undergo "living" polymerization under both ATRP and SFRP conditions, the diene complex $\mathrm{CpMoCl}_{2}\left(\eta^{4}-\right.$ $\mathrm{C}_{4} \mathrm{H}_{6}$ ) undergoes "living" polymerization only under SFRP conditions and CCT under ATRP conditions. All these features have been rationalized on the basis of a global kinetic scheme and simulation tests [15]. In order to broaden our understanding of this phenomenon, we have tested our new diazadiene (dad) complexes in the controlled radical polymerization of styrene and the related results are also presented here.

$<$ Scheme 1>

\section{Experimental}

General. All manipulations were carried out under an atmosphere of dry and oxygenfree argon with standard Schlenk techniques. Styrene was washed with an aqueous $\mathrm{NaOH}$ solution (10\%), neutralized with water, dried over $\mathrm{MgSO}_{4}$ and then distilled at $25^{\circ} \mathrm{C}$ under reduced pressure. Toluene and pentane were purified by reflux over sodium benzophenone ketyl and distilled under argon prior to use. $\mathrm{CH}_{2} \mathrm{Cl}_{2}$ was purified from $\mathrm{P}_{4} \mathrm{O}_{10}$ and distilled under argon. Molecular weights and molecular weight distributions were measured with a Gynkoteck P580 size exclusion chromatographer equipped with a refractometer and 2 B Jordi DVB columns (range 1000-1000000) using THF as eluent (1 mL/min). The instrument was 
calibrated by using polystyrene standards. EPR measurements were carried out at the X-band microwave frequency on a Bruker ESP300 spectrometer. The spectrometer frequency was calibrated with diphenylpicrylhydrazyl $(\mathrm{DPPH}, \mathrm{g}=2.0037)$. Cyclic voltammograms were recorded with an EG\&G 362 potentiostat connected to a Macintosh computer through MacLab hardware/sofware. The electrochemical cell was fitted with an $\mathrm{Ag}-\mathrm{AgCl}$ reference electrode, a platinum disk working electrode and a platinum wire counter-electrode. $\left[\mathrm{Bu}_{4} \mathrm{~N}\right] \mathrm{PF}_{6}($ ca. $0.1 \mathrm{M})$ was used as supporting electrolyte in THF. All potentials are reported relative to the ferrocene standard, which was added to each solution and measured at the end of the experiments. The elemental analyses were carried out by the analytical service of LSEO with a Fisons EA 1108 instrument. $\left[\mathrm{CpMo}(\mu-\mathrm{Cl})_{2}\right]_{2}$ was obtained according to a previously described synthetic procedures [18], and the $N, N$-disubstituted 1,4-diaza-1,3-diene ligands $\left(\mathrm{R}_{2}\right.$-dad, with $\mathrm{R}=\mathrm{Ph}, p-\mathrm{Tol}, \mathrm{C}_{6} \mathrm{H}_{3} \mathrm{Pr}_{2}{ }_{2}-2,6$, and $\left.\mathrm{i}-\mathrm{Pr}\right)$ were prepared as described in the literarure [19-22]. 1-Bromophenylethane was purchased from Aldrich Chemical Co and degassed prior to use. Azobis(isobutyronitrile) (JANSSEN) was recrystallized twice from $\mathrm{MeOH}$ before use.

Synthesis of CpMoCl $2(\mathbf{P h} 2-d a d), 1:\left[C p M o(\mu-C l)_{2}\right]_{2}(0.204$ g, $0.44 \mathrm{mmol})$ and $\mathrm{Ph}_{2}$-dad ( $0.183 \mathrm{~g}, 0.88 \mathrm{mmol})$ were suspended in $20 \mathrm{~mL}$ of $\mathrm{CH}_{2} \mathrm{Cl}_{2}$ at room temperature. The mixture was then stirred for several hours (ca. 20). The solution was filtered through Celite to remove a small amount of residual solid and concentrated under reduced pressure to ca. $4 \mathrm{~mL}$. Addition of $10 \mathrm{~mL}$ of pentane gave complex $\mathbf{1}$ as a red brown microcrystalline solid, which was washed with pentane ( 3 x $5 \mathrm{~mL})$ and dried in vacuo. Yield: $0.2341 \mathrm{~g}(60 \%)$. Anal. Calcd for $\mathrm{C}_{19} \mathrm{H}_{17} \mathrm{Cl}_{2} \mathrm{MoN}_{2}$ (440.20): C, 51.84; H, 3.89; N, 6.36. Found: C, 52.46; H, 4.06; N, 6.46. EPR $\left(\mathrm{CH}_{2} \mathrm{Cl}_{2}\right): \mathrm{g}=1.968\left(\mathrm{a}_{\mathrm{Mo}}=38.7 \mathrm{G}\right)$. Cyclic voltammetry $(\mathrm{THF})$ : irreversible oxidation with $\mathrm{E}_{\mathrm{p}, \mathrm{a}}=-0.01 \mathrm{~V}$ and reversible reduction at $\mathrm{E}_{1 / 2}=-1.12 \mathrm{~V}\left(\Delta \mathrm{E}_{\mathrm{p}}=71 \mathrm{mV}\right)$. The ferrocene peak showed $\Delta \mathrm{E}_{\mathrm{p}}=76 \mathrm{mV}$. 
Synthesis of $\mathbf{C p M o C l}_{2}(\boldsymbol{p}$-Tol2-dad $), 2$ : $\left[\mathrm{CpMo}(\mu-\mathrm{Cl})_{2}\right]_{2}(0.195 \mathrm{~g}, 0.42 \mathrm{mmol})$ and $p$ $\mathrm{Tol}_{2}$-dad $(0.200 \mathrm{~g}, 0.85 \mathrm{mmol})$ were suspended in $8 \mathrm{~mL}$ of toluene at room temperature. The mixture was then stirred for several hours (ca. 20) at $70^{\circ} \mathrm{C}$. Dichloromethane $(20 \mathrm{~mL})$ was added at room temperature and the solution was filtered through Celite to remove a small amount of residual solid and evaporated to dryness under reduced pressure to give complex 2 as a red brown microcrystalline solid. Yield: $0.276 \mathrm{~g}$ (70\%). Anal. Calcd for $\mathrm{C}_{21} \mathrm{H}_{21} \mathrm{Cl}_{2} \mathrm{MoN}_{2}$ (468.26): C, 53.87; H, 4.52; N, 5.98. Found: C, 52.92; H, 4.64; N 5.56. EPR (toluene): $\mathrm{g}=$ $1.969\left(\mathrm{a}_{\mathrm{Mo}}=38.9 \mathrm{G}\right)$. Cyclic voltammetry $(\mathrm{THF})$ : irreversible oxidation at $\mathrm{E}_{\mathrm{p}, \mathrm{a}}=0.00$ and irreversible reduction at $E_{p, a}=-0.99 \mathrm{~V}$. The reduction wave is observed at $E_{p, a}=-0.89 \mathrm{~V}$ in $\mathrm{CH}_{2} \mathrm{Cl}_{2}$ and becomes reversible after addition of $\mathrm{Cl}^{-}$while it shifts to $\mathrm{E}_{1 / 2}=-0.895 \mathrm{~V}\left(\mathrm{E}_{\mathrm{p}, \mathrm{a}}=-\right.$ 0.93 V), see Results section.

Synthesis of $\mathbf{C p M o C l}_{2}\left[\left(\mathbf{C}_{6} \mathbf{H}_{3} \mathbf{P r}^{\mathrm{i}}{ }_{2}-\mathbf{2}, \mathbf{6}\right)_{2}-\mathbf{d a d}\right], 3:\left[\mathrm{CpMo}(\mu-\mathrm{Cl})_{2}\right]_{2} \quad(0.3013 \mathrm{~g}, 0.65$ mmol $)$ and $\left(\mathrm{C}_{6} \mathrm{H}_{3} \mathrm{Pr}_{2}{ }_{2}-2,6\right)_{2}-$ dad $(0.506 \mathrm{~g}, 1.34 \mathrm{mmol})$ were suspended in $10 \mathrm{~mL}$ of toluene at room temperature. The mixture was then stirred for 4 days at $70^{\circ} \mathrm{C}$. The solution was filtered through Celite and dried in vacuo to give an oily residue. Addition of $5 \mathrm{~mL}$ of pentane gave complex $\mathbf{3}$ as a red-brown microcrystalline solid, which was washed with pentane $(2 \times 5 \mathrm{~mL})$ and dried in vacuo. Yield: $0.502 \mathrm{~g}$ (70\%). Anal. Calcd for $\mathrm{C}_{31} \mathrm{H}_{41} \mathrm{Cl}_{2} \mathrm{MoN}_{2}$ (608.52): $\mathrm{C}$, 61.19; H, 6.79; N, 4.60. Found: C, 61.52; H, 6.83; N, 4.68. EPR (toluene): $\mathrm{g}=1.989$ (aMo $=$ $38.0 \mathrm{G})$. Recrystallization by slow cooling of a hot heptane solution afforded crystals of $\mathbf{3}$, which were used for the X-ray analysis. Cyclic voltammetry (THF): irreversible oxidation at $\mathrm{E}_{\mathrm{p}, \mathrm{a}}=0.33 \mathrm{~V}$ and irreversible reduction at $\mathrm{E}_{\mathrm{p}, \mathrm{c}}=-1.01 \mathrm{~V}$.

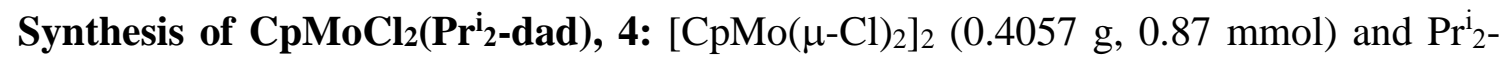
dad $(0.378 \mathrm{~g}, 2.69 \mathrm{mmol})$ were suspended in $20 \mathrm{~mL}$ of toluene at room temperature. The mixture was then stirred for two days at $70^{\circ} \mathrm{C}$. The resulting solution was evaporated to dryness under reduced pressure and the residue was further dried under vacuum at $70^{\circ} \mathrm{C}$ to sublime the residual $\operatorname{Pr}_{2}^{\mathrm{i}}$-DAD. The product was extracted with $40 \mathrm{~mL}$ of $\mathrm{CH}_{2} \mathrm{Cl}_{2}$, the 
resulting solution was filtered through Celite and then evaporated to dryness to yield a dark red microcrystalline solid. Yield: $0.4172 \mathrm{~g}$ (64\%). Anal. Calcd for $\mathrm{C}_{13} \mathrm{H}_{21} \mathrm{Cl}_{2} \mathrm{MoN}_{2}$ (372.17): C, 41.95; H, 5.69; N, 7.53. Found C, 42.29; H, 5.80; N, 7.69. EPR $\left(\mathrm{CH}_{2} \mathrm{Cl}_{2}\right): \mathrm{g}=1.975\left(\mathrm{a}_{\mathrm{Mo}}=\right.$ $42.8 \mathrm{G})$. Cyclic voltammetry (THF): reversible oxidation at $\mathrm{E}_{1 / 2}=0.01 \mathrm{~V}\left(\Delta \mathrm{E}_{\mathrm{p}}=90 \mathrm{mV}\right)$ and reversible reduction at $\mathrm{E}_{1 / 2}=-1.10 \mathrm{~V}\left(\Delta \mathrm{E}_{\mathrm{p}}=80 \mathrm{mV}\right)$. The ferrocene peak showed $\Delta \mathrm{E}_{\mathrm{p}}=110$ $\mathrm{mV}$.

ATRP polymerizations. All ATRP polymerization reactions were performed following the same experimental procedure. The complex was added to a $50 \mathrm{~mL}$ Schlenk tube equipped with a stirring bar. Styrene and 1-bromophenylethane were added to the reaction flask by a syringe. The Schlenk tube was then immersed in an oil bath heated at $90^{\circ} \mathrm{C}$. Aliquots were withdrawn periodically for a reaction monitoring by GPC.

SFRP polymerization. SFRP polymerizations were conducted as follows: the Mo complex and AIBN were added to a $50 \mathrm{~mL}$ Schlenk tube equipped with a stirring bar. Styrene was added by a syringe. The Schlenk tube was immersed in an oil bath heated at $100^{\circ} \mathrm{C}$. Aliquots were withdrawn periodically for a reaction monitoring by GPC.

X-ray analysis of compound 3. Intensity data were collected on a Nonius Kappa CCD at $110 \mathrm{~K}$. The structure was solved via a Patterson search program and refined with fullmatrix least-squares methods based on $\mathrm{F}^{2}$ (SHELXL-97)[23] with the aid of the WINGX program.[24] All non-hydrogen atoms were refined with anisotropic thermal parameters. Hydrogen atoms were included in their calculated positions or found in the final difference Fourier maps and refined with a riding model. The crystal data and refinement parameters are collected in Table 1. 


\section{(a) Synthesis and EPR characterization}

The synthesis of the title compounds is accomplished by the straightforward addition of the appropriate diazadiene ligand $\mathrm{RN}=\mathrm{CH}-\mathrm{CH}=\mathrm{NR}\left(\mathrm{R}_{2}\right.$-dad; $\mathrm{R}=\mathrm{Ph}, p-\mathrm{Tol}, \mathrm{C}_{6} \mathrm{H}_{3} \mathrm{Pr}_{2}{ }_{2}-2,6$, and $\operatorname{Pr}^{\mathrm{i}}$ ) to $\left[\mathrm{CpMoCl}_{2}\right]_{2}$, see Equation 1. The resulting complexes have been isolated as stable crystalline solids in good yields and fully characterized. They are air sensitive in the solid state and in solution but can be easily handled under an inert atmosphere.

$<$ Equation $1>$

Like the previously characterized members of the same family, these compounds exhibit sharp EPR signals in homogeneous solutions at room temperature, in agreement with their formulation as mononuclear metalloradicals and with the absence of low-lying excited states. The g parameter for all compounds is quite close the spin-only value and the Mo hyperfine splittings are around $40 \mathrm{G}$, the alkyl substituted member (4) having a slightly greater coupling than the aryl substituted ones (1-3).

\section{(b) Structural characterization of compound 3}

The mononuclear nature of complexes $\mathbf{1 - 4}$ is verified in one case (compound $\mathbf{3}$ ) by a single crystal X-ray analysis. Two different views of the molecule are shown in Figure 1 and Figure 2. Selected bond distances and angles are listed in Table 2. The most interesting geometrical feature is the arrangement adopted by the 5-membered ring containing the metal atom and the diazadiene ligand. This ligand system may adopt a variety of coordination modes and examples are known in the literature which can be most closely described as either $\mathbf{A}, \mathbf{B}$ or $\mathbf{C}$ [25]. For compound 3, the 5-membered ring is essentially planar (Rms deviation of fitted atoms $=0.07$; highest deviation from the plane: $0.0842 \AA$ for atom N1). The fit of the 
$\mathrm{N}_{2} \mathrm{C}_{2}$ plane is even better ( $\mathrm{Rms}$ deviation of fitted atoms $\left.=0.002\right)$, this plane having a small dihedral angle with the $\mathrm{MoN}_{2}$ plane $\left[11.42(9)^{\circ}\right]$, as can be easily appreciated from Figure 2 . This excludes the arrangement $\mathbf{C}$, which is characterized by a rather severe folding around the N-N hinge.

\section{$<\mathrm{A} \mathrm{B} \mathrm{C}>$}

It is also interesting to observe that the N-C and C-C distances of the dad ligand are considerably lengthened and shortened, respectively, when compared with those of free dad molecules such as s-trans-Cy2dad (N-C: 1.258(2) $\AA$; C-C: 1.457(2) $\AA$ ) and also with those of complexes to which the bonding mode A can be clearly assigned (N-C: $1.26-1.30 \AA$ A; $\mathrm{C}-\mathrm{C}$ : 1.40-1.46 А).[25] The observed bonding parameters are more consistent with a bonding description where the arrangement $\mathbf{B}$ plays a significant role. This limiting form corresponds to an enediamido complex of $\mathrm{Mo}(\mathrm{V})$. There is an interesting similarity between this situation and that of the analogous diene systems [26-28] for which contribution of an $\eta^{4}$-diene Mo(III) formulation as well as an enediyl $\mathrm{Mo}(\mathrm{V})$ formulation is invoked, though the former seems to predominate [27]. Another interesting point of discussion is the remarkable structural change undergone by the $\mathrm{CpMCl}_{2}$ (dad) system on going from $\mathrm{Nb}$ and $\mathrm{Ta}$ (for which the C-type arrangement is always observed [10-14]) to molybdenum. It seems reasonable to attribute this change to the presence of one additional electron on the Group 6 metal. Therefore, the 6electron coordination mode for the ligand in $\mathbf{C}$ would lead to an unfavorable 19-electron configuration.

Complex $\mathbf{3}$ appears to be the first crystallographically characterized diazadiene complex of molybdenum(III). The Mo-N distances are considerably shorter than in the structurally related half-sandwich $\mathrm{Mo}(\mathrm{II})$ complex $\left[\mathrm{CpMo}\left(\mathrm{H}_{2} \mathrm{Biim}\right)(\mathrm{CO})_{2}\right]^{+}\left(\mathrm{H}_{2} \mathrm{Biim}=\right.$ bisimidazole; 2.17(2) and 2.21(2) $\AA$ ),[29] and also shorter than the higher oxidation state $\mathrm{MoO}_{2} \mathrm{Cl}_{2}\left(\mathrm{Bu}^{\mathrm{t}}{ }^{\mathrm{t}}\right.$ - 
dad) $(2.399(2)$ and 2.388(2) $\AA$ ) [30]. This is supporting evidence for the description of the coordination geometry as B. Analogously, the $\mathrm{Mo}-\mathrm{Cl}$ distances are shorter than those found for $\mathrm{CpMoCl}_{2}\left(\mathrm{PMe}_{3}\right)_{2}\left(2.468(2)\right.$ and 2.474(2) $\AA$ ) [31] and $\mathrm{CpMoCl}_{2}\left(\eta^{4}-\mathrm{C}_{4} \mathrm{H}_{6}\right)(2.435(1)$ and 2.433(1) $\AA$ ) [26], in further agreement with the assignment of a higher formal oxidation state to the metal in compound 3.

$<$ Figure 1, Figure 2 and Table $2>$

\section{(c) Electrochemical characterization}

The electrochemical properties of compounds 1-4 reflect the degree of electron donation provided by the diazadiene ligands with respect to other ligands in similar compounds (see Table 3). All the compounds exhibit two one-electron processes, one reduction and one oxidation.

$<$ Table 3>

The potentials associated to the one-electron oxidation process are more positive in the order (phosphine $<$ diazadiene $<$ alkyne $<$ diene), whereas those associated to the one-electron reduction process are less negative in the order (phosphine $<$ diene, alkyne $<$ diazadiene). While both trends agree in showing that the phosphine ligands are the best electron donors, the inversion between the diene and alkyne on one side and the diazadiene on the other side is unexpected. This inversion can be reconciled by the fact that the molecular orbital involved in the redox process is not necessarily the same for the oxidation and the reduction. The different ligands may have a different effect on each orbital via a different type of interaction. In fact, while the reduction most probably involves the singly occupied orbital, yielding a closed-shell 18-electron configuration, the oxidation process may involve the second highest 
occupied $\mathrm{MO}$, at least in the diazadiene case. A few phosphine-containing oxidation products have been isolated and shown to possess a spin triplet ground state. For the alkyne and diene complexes, the spin state of the oxidation products is unknown since these are unstable complexes.

Curiously, the oxidation occurs approximately at the same potential for the aryl substituted (1 and 2) and alkyl substituted (4) complexes, for which an electronic difference may be expected, whereas the potential is significantly more positive for the aryl-substituted complex 3. These trends do not have a straightforward rationalization, but we note that the steric bulk of the $\mathrm{C}_{6} \mathrm{H}_{3} \operatorname{Pr}_{2}^{\mathrm{i}}{ }_{2}$ substituents may weaken the donor properties of the dad ligand relative to the other dad ligands, making the metal electron-poorer and consequently more difficult to oxidize.

The reduction waves are found in the narrow range between -0.99 and $-1.12 \mathrm{~V}$ for the entire family of complexes. We should also mention the possibility that the reduction processes are ligand-based rather than metal-based, since we find that the free ligands can also be reversibly reduced in THF. If this is the case, however, coordination would cause a rather high positive shift $(>1 \mathrm{~V})$ since the measured $\mathrm{E}_{1 / 2}$ are $-2.23 \mathrm{~V}$ for $\left(\mathrm{C}_{6} \mathrm{H}_{3} \mathrm{Pr}_{2}^{\mathrm{i}}\right)_{2}$-dad and -2.02 V for $p$-Tol 2 -dad.. A greater insight into this problem could only be obtained by theoretical studies or by isolation and spectroscopic/magnetic characterization of the reduction product.

The reduction process shows electrochemical reversibility in THF for compounds $\mathbf{1}$ and 4, whereas the return oxidation wave has a lower intensity for compounds $\mathbf{2}$ and $\mathbf{3}$, indicating that the reduction is followed by a relatively fast follow-up chemical process. The nature of this process has been clarified by more detailed studies in the presence of variable amounts of added $\mathrm{Cl}^{-}$salts, which were carried out in $\mathrm{CH}_{2} \mathrm{Cl}_{2}$ for solubility reasons. The general shape of the voltammograms and the potential values in the absence of chloride did not vary greatly on going from THF to $\mathrm{CH}_{2} \mathrm{Cl}_{2}$, except that the processes were less chemically reversible in $\mathrm{CH}_{2} \mathrm{Cl}_{2}$. Even the reduction of compound 1 lost reversibility when carried out in this solvent. 
The reduction wave becomes, however, more reversible in the presence of excess free chloride while the reduction potential shifts toward more negative values, as shown in Figure 3 for the representative case of compound 2. This behavior is consistent with chloride dissociation from the reduced 18-electron product as the chemical follow-up process, as proposed in Scheme 2. The chloride loss must be a reversible process, whereas the product of chloride loss must be electrochemically inactive or undergo an oxidation process at a more positive potential.

$<$ Figure 3 and Scheme $2>$

\section{(d) Controlled radical polymerization of styrene}

Complexes 1-4 are all active catalysts for the controlled radical polymerization of styrene under ATRP conditions (see Scheme 1) using (1-bromoethyl)benzene (BEB) as initiator. The controlled nature of the polymerization processes is indicated by the slow and linear growth of the average molecular weight with conversion, by the good correspondence between the experimental and the theoretical number-average molecular weight $\left(M_{n}\right)$ values, and by the relatively low polydispersity indexes $\left(\mathrm{PDI}=\mathrm{M}_{\mathrm{w}} / \mathrm{M}_{\mathrm{n}}\right.$ where $\mathrm{M}_{\mathrm{w}}=$ weight-average molecular weight). An example is shown in Figure 4 for the polymerization with complex 4, while all measurements are available as Supplementary Material. The experimental $M_{n}$ values are slightly lower than the theoretical ones when using compounds $\mathbf{1 , 2}$ and $\mathbf{3}$, and slightly larger when using compound $\mathbf{4}$, but the match is overall quite good.

The polymerization kinetics are first order in monomer and provide the following values for the apparent propagation constant in $\mathrm{s}^{-1}: 1.42 \times 10^{-4}$ for $1,0.22 \times 10^{-4}$ for $2,1.20 \times 10^{-4}$ for 3 and $0.61 \times 10^{-4}$ for 4 , all in bulk at $90^{\circ} \mathrm{C}$. This apparent rate constant is given by the expression in Equation $2\left(\mathrm{k}_{\mathrm{p}}=\right.$ propagation rate constant; $\mathrm{K}_{\mathrm{ATRP}}=$ equilibrium constant of the ATRP equilibrium in Scheme 1). Since $k_{p}$ is the same for all cases, these values should 
reflect the relative position of the ATRP equilibrium. However, while the concentrations of catalyst (M) and initiator (RX) have been chosen identical in the different experiments, that of the atom transferred complex $(\mathrm{M}-\mathrm{X})$ is highly dependent on the amount of bimolecular terminations that occur during the initial phase of the polymerization process. Therefore, no conclusions concerning the relative values of the $\mathrm{K}_{\text {ATRP }}$ can be made in the absence of more detailed kinetic investigations.

$<$ Figure 4 and Equation 2>

As phosphine containing half-sandwich complexes of Mo(III) have provided the first example of systems that are capable of controlling the radical polymerization by both ATRP and SFRP mechanisms simultaneously, whereas the analogous butadiene system leads to controlled polymerization only under SFRP conditions (see Introduction), it was of interest to verify whether the diazadiene systems are capable of functioning as reversible spin traps for SFRP leading to a "living" polymerization process.

Indeed, complex 3 leads to the controlled/'living" polymerization of styrene when thermolyzed in situ with AIBN (azoisobutirronitrile), see Figure 5. Like for the ATRP polymerization described above, the polymer $M_{n}$ grows slowly and linearly with conversion, it is close to the theoretical value (under the assumption of a radical production efficiency $f=$ 1 for the AIBN thermolysis), and the PDI values are relatively low. The other complexes (1, 2 and 4) have not been tested under the same conditions, but there is little doubt that they would also be capable of controlling the SFRP of styrene.

$<$ Figure 5 $>$ 
The results shown above indicate that at least one half-sandwich diazadiene molybdenum complex is able to control both the ATRP and the SFRP of styrene, like related phosphine-containing half-sandwich Mo(III) complexes.[15] The fact that the ATRP equilibrium must forcedly be shifted towards $\mathrm{M}$ and $\mathrm{RX}$ means that the $\mathrm{M}$ concentration will be significant under dynamic equilibrium conditions. In turn, this condition favors the engagement of the SFRP equilibrium for trapping the reactive radical. Therefore, both the ATRP and SFRP dormant species (R-X and M-R) are present simultaneously when the experiment is carried out under ATRP conditions, as discussed earlier [15].

In our previous controlled radical polymerization study [15], it was established that the system ability to afford controlled polymerization by either the stable free radical or the atom transfer mechanism is closely related to the strength of the Mo-R bond in the first case and the Mo-X and R-X bonds in the other case. It was further established that these strengths do not depend on the nature of the ligands in a dramatic way. In line with these arguments, the related diazadiene complexes reported here are also able to undergo controlled polymerization by both mechanisms. While the radical polymerization was found to be "living" with both phosphine and $\eta^{4}$-diene complexes under SFRP conditions, however, only the phosphine systems gave "living" polymerization under ATRP conditions. The diene complex leads to catalyzed chain transfer. This difference was attributed to the different steric protection assured by the different ligands. While the high concentration of the Mo(III) complex (which is the chain transfer catalyst) under ATRP conditions should always favor the transfer process, the bulkier phosphines ligand protect the metal center from the close approach of the reactive radical, thereby slowing the rate-determining event of the chain transfer process, namely the $\mathrm{H}$ atom transfer to form a Mo(IV) hydride complex. Under the validity of this hypothesis, the results reported here for the diazadiene derivatives indicate that the bulk increase on going from $\mathrm{CH}_{2}=\mathrm{CH}-\mathrm{CH}=\mathrm{CH}_{2}$ to $\mathrm{RN}=\mathrm{CH}-\mathrm{CH}=\mathrm{NR}$ is already sufficient to slow down the $\mathrm{H}$ atom transfer process. 


\section{Conclusion}

Members of the 17-electron $\mathrm{CpMoCl}_{2} \mathrm{~L}_{2}$ family where both L ligands are nitrogen donors have been synthesized for the first time. Back-bonding to the diazadiene ligand is substantial, yielding a structure where the $\mathrm{Mo}(\mathrm{V})$-enediamido limiting form contributes in a substantial way. The electrons of the central ene function, however, do not participate in the bonding contrary to the Group 5 analogues. Like previously investigated 17-electron halfsandwich complexes of molybdenum, these compounds are capable of controlling the radical polymerization of styrene to yield "living" polymers under both SFRP and ATRP conditions. We are now extending the application of these and other molybdenum complexes to the polymerization of other monomers.

\section{Supplementary Material}

Crystallographic data for the structural analysis have been deposited with the Cambridge Crystallographic Data Centre, CCDC No. 189193. Copies of this information may be obtained free of charge from The Director, CCDC, 12 Union Road, Cambridge, CB2 1EZ, UK (Fax: +44-1223-336033; E-mail: deposit@ccdc.cam.ac.uk or www:

http://www.ccdc.cam.ac.uk). Tables of conversions, experimental and theoretical $\mathrm{M}_{\mathrm{n}}$, and PDI vs. time for the ATRP and SFRP experiments (2 pages) are available from the principal author.

\section{Acknowledgement}

We are grateful to the French Ministery of Research and to the CNRS for funding, to Dr. Mikhail Vorotyntsev for helpful discussion, and to Mr. B. Rebière for his technical assistance. 


\section{References}

1 R. Poli, J. Coord. Chem. B 29 (1993) 121-173.

2 J. C. Fettinger, D. W. Keogh and R. Poli, J. Am. Chem. Soc. 118 (1996) 3617-3625.

3 J. C. Fettinger, H.-B. Kraatz, R. Poli and E. A. Quadrelli, J. Chem. Soc., Dalton Trans. (1999) 497-508.

4 E. Le Grognec, R. Poli and P. Richard, J. Chem. Soc., Dalton Trans. (2001) 22512257.

5 P. D. Grebenik, M. L. H. Green, A. Izquierdo, V. S. B. Mtetwa and K. Prout, J. Chem. Soc., Dalton Trans. (1987) 9-19.

6 M. D. Fryzuk, L. Jafarpour and S. J. Rettig, Organometallics 18 (1999) 4050-4058.

7 J. L. Davidson, K. Davidson and W. E. Lindsell, J. Chem. Soc., Chem. Commun. (1983) 452-453.

8 D. Morales, R. Poli, P. Richard, J. Andrieu and E. Collange, J. Chem. Soc., Dalton Trans. (1999) 867-874.

9 J. Andrieu, P. Braunstein, J.-M. Camus, D. Morales, F. Naud, R. Poli and P. Richard, J. Chem. Soc., Dalton Trans. (2000) 2577-2585.

10 H. Kawaguchi, Y. Yamamoto, K. Asaoka and K. Tatsumi, Organometallics 17 (1998) 4380-4386.

11 K. Mashima, Y. Matsuo and K. Tani, Organometallics 18 (1999) 1471-1481.

12 A. Nakamura and K. Mashima, J. Organometal. Chem. 621 (2001) 224-230.

13 Y. Matsuo, K. Mashima and K. Tani, Angew. Chem., Int. Ed. Engl. 40 (2001) 960962.

14 Y. Matsuo, K. Mashima and K. Tani, Organometallics 21 (2002) 138-143.

15 E. Le Grognec, J. Claverie and R. Poli, J. Am. Chem. Soc. 123 (2001) 9513-9524.

16 K. Matyjaszewski and J. H. Xia, Chem. Rev. 101 (2001) 2921-2990.

17 B. Wayland, G. Poszmick and S. Mukerjee, J. Am. Chem. Soc. 116 (1994) 7943-7944.

$18 \quad$ F. Abugideiri and R. Poli, in 'Bis $\{\mu$-dichloro( $\eta$ pentamethylcyclopentadienyl)molybdenum $\}$ (Mo-Mo) - $\left\{\mathrm{Mo}\left(\eta-\mathrm{C}_{5} \mathrm{Me}_{5}\right)(\mu-\mathrm{Cl})_{2}\right\}_{2}$, ed. W. A. Herrmann, Stuttgart, 1997.

19 J. M. Kliegman and R. K. Barnes, J. Org. Chem. 35 (1970) 3140-3143.

20 J. M. Kliegman and R. K. Barnes, Tetrahedron 26 (1970) 2555-2560.

21 H. tom Dieck and I. W. Renk, Chem. Ber. 104 (1971) 92-109.

22 L. Jafarpour, E. D. Stevens and S. P. Nolan, J. Organomet. Chem. 606 (2000) 49-54.

23 G. M. Sheldrick, 'SHELX97 (Includes SHELXS97 and SHELXL97), Release 97-2, Programs for Crystal Structure Analysis', University of Göttingen, 1998.

24 L. J. Farrugia, J. Appl. Crystallogr. 32 (1999) 837-838.

25 G. Van Koten and K. Vrieze, Advances in Organometallic Chemistry 21 (1982) 151239, and references therein.

26 J. L. Davidson, K. Davidson, W. E. Lindsell, N. W. Murrall and A. J. Welch, J. Chem. Soc., Dalton Trans. (1986) 1677-1688.

27 L.-S. Wang, J. C. Fettinger and R. Poli, J. Am. Chem. Soc. 119 (1997) 4453-4464.

28 R. Poli and L.-S. Wang, J. Am. Chem. Soc. 120 (1998) 2831-2842.

29 M. G. B. Drew, V. Felix, I. S. Goncalves, F. E. Kuhn, A. D. Lopes and C. C. Romao, Polyhedron 17 (1998) 1091-1102.

$30 \quad$ K. Dreisch, C. Andersson and C. Stalhandske, Polyhedron 12 (1993) 303-311.

31 S. T. Krueger, R. Poli, A. L. Rheingold and D. L. Staley, Inorg. Chem. 28 (1989) 4599-4607.

32 E. Le Grognec, R. Poli and P. Richard, Organometallics 19 (2000) 3842-3853. 
33 E. Le Grognec, R. Poli and P. Richard, J. Chem. Soc., Dalton Trans. (2000) 14991506.

34 S. T. Krueger, B. E. Owens and R. Poli, Inorg. Chem. 29 (1990) 2001-2006. 
Table 1. Crystal data and structure refinement for compound 3.

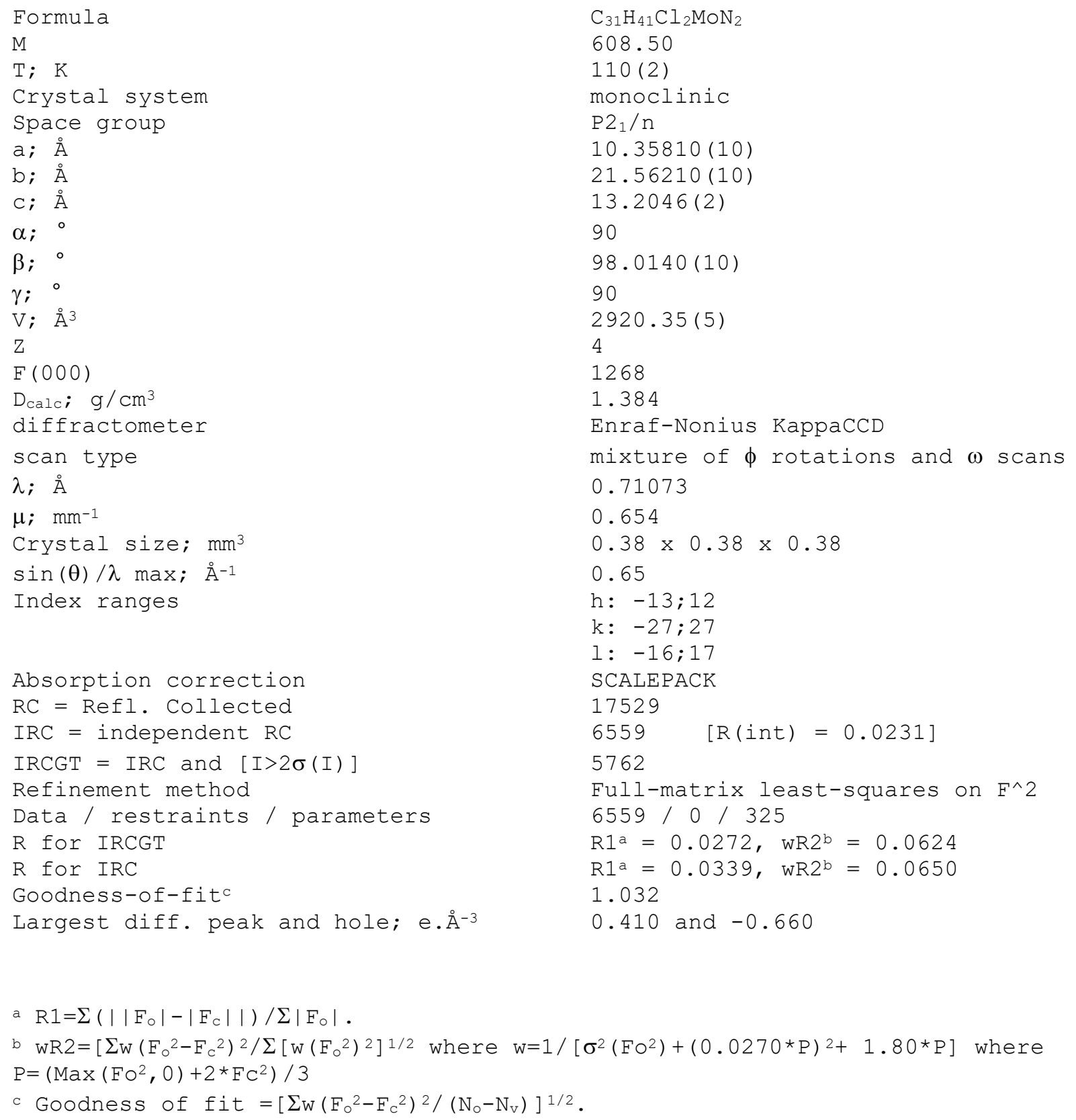


Table 2. Bond lengths $[\AA]$ and angles $\left[{ }^{\circ}\right]$ for compound 3 . $^{\text {a }}$

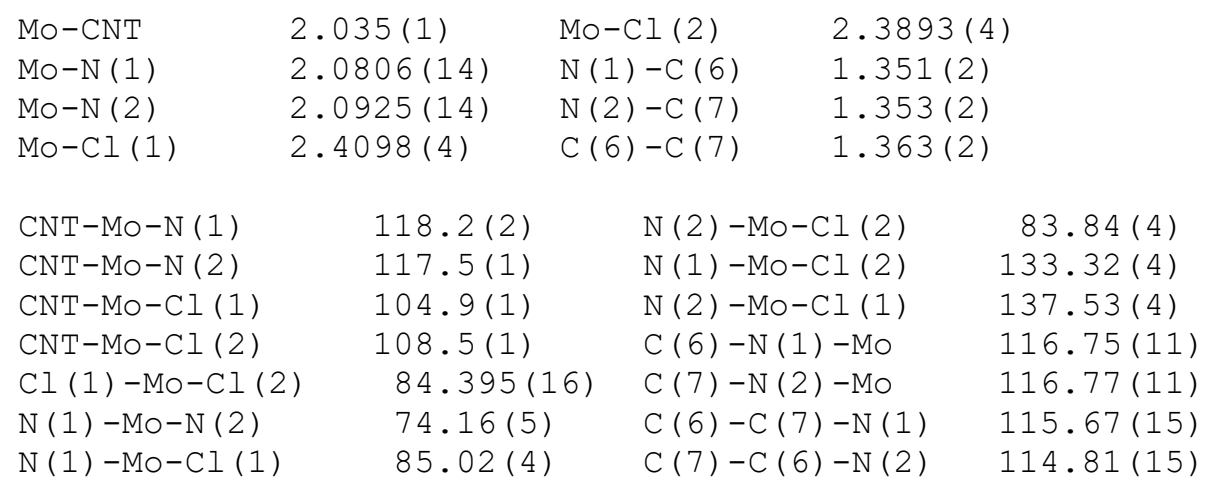

${ }^{\mathrm{a}} \mathrm{CNT}=$ cyclopentadienyl ring centroid 
Table 3. Electrochemical properties of compounds 1-4 and comparison with representative similar compounds.

\begin{tabular}{|c|c|c|c|c|}
\hline Compound & Reduction $^{\mathrm{a}}$ & Oxidation $^{\mathrm{a}}$ & Solv. & Ref. \\
\hline $\mathrm{CpMoCl}_{2}\left(\eta^{4}-\mathrm{C}_{4} \mathrm{H}_{6}\right)$ & -1.11 & $+0.73^{\mathrm{b}}$ & THF & {$[32]$} \\
\hline $\mathrm{CpMoCl}_{2}(\mathrm{PhC} \equiv \mathrm{CPh})$ & -1.14 & $+0.32^{\mathrm{b}}$ & THF & {$[33]$} \\
\hline $\mathrm{CpMoCl}_{2}(\mathrm{EtC} \equiv \mathrm{CEt})$ & -1.33 & $+0.16^{\mathrm{b}}$ & THF & {$[33]$} \\
\hline 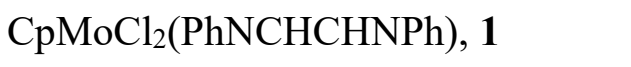 & -1.12 & $-0.01^{b}$ & THF & This work \\
\hline $\mathrm{CpMoCl}_{2}(p-$ TolNCHCHN- $p$-Tol), 2 & $-0.99^{c}$ & $0.00^{\mathrm{b}}$ & THF & This work \\
\hline $\mathrm{CpMoCl}_{2}(\mathrm{ArNCHCHNAr})^{\mathrm{d}}, \mathbf{3}$ & $-1.01^{\mathrm{c}}$ & $+0.33^{\mathrm{b}}$ & THF & This work \\
\hline $\mathrm{CpMoCl}_{2}\left(\operatorname{Pr}^{\mathrm{i} N C H C H N P r}{ }^{\mathrm{i}}\right), 4$ & -1.10 & +0.01 & THF & This work \\
\hline $\mathrm{CpMoCl}_{2}(\mathrm{dppe})$ & $-1.91^{\mathrm{c}, \mathrm{e}}$ & -0.33 & $\mathrm{CH}_{2} \mathrm{Cl}_{2}$ & {$[34]$} \\
\hline $\mathrm{CpMoCl}_{2}\left(\mathrm{PMe}_{3}\right)_{2}$ & & -0.52 & $\mathrm{CH}_{2} \mathrm{Cl}_{2}$ & [31] \\
\hline
\end{tabular}

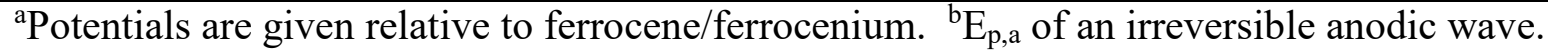
${ }^{\mathrm{c}} \mathrm{E}_{\mathrm{p}, \mathrm{c}}$ of an irreversible cathodic wave. ${ }^{\mathrm{d}} \mathrm{Ar}=2,6-\mathrm{C}_{6} \mathrm{H}_{3} \mathrm{Pr}_{2}{ }_{2}$. ${ }^{\mathrm{e}} \mathrm{In} \mathrm{THF}$ (no reduction process is observed in $\mathrm{CH}_{2} \mathrm{Cl}_{2}$ before the solvent discharge). 


\section{Captions for Figures}

Figure 1. An ORTEP view of the geometry of compound 3.

Figure 2. A side view of the geometry of compound 3, emphasizing the perpendicular orientation of the dad aryl substituent relative to the coordination plane.

Figure 3. Cyclic voltammetric response for a solution of compound $2\left(1.9 \times 10^{-3} \mathrm{M}\right)$ in $\mathrm{CH}_{2} \mathrm{Cl}_{2}$ in the presence of added tetrabutylammmonium chloride. $\mathrm{Cl}^{-} / \mathrm{Mo}=0$ (a); 23 (b); 70 (c).

Figure 4. $\quad \mathrm{M}_{\mathrm{n}}$ and PDI vs. conversion for polystyrene obtained by ATRP (bulk, $90^{\circ} \mathrm{C}$ ) in the presence of complex 4 and BEB (4/BEB/styrene $=1 / 1 / 390)$. Diamonds: experimental $\mathrm{M}_{\mathrm{n}}$ values; squares: theoretical $\mathrm{M}_{\mathrm{n}}$ values; circles: PDI values.

Figure 5. $\quad \mathrm{M}_{\mathrm{n}}$ and PDI vs. conversion for polystyrene obtained by SFRP (bulk, $100^{\circ} \mathrm{C}$ ) in the presence of complex 3 and AIBN (3/AIBN/styrene =1/0.5/347). Black spheres: experimental $M_{n}$ values; open squares: theoretical $M_{n}$ values. Open triangles: PDI values. 
Figure 1

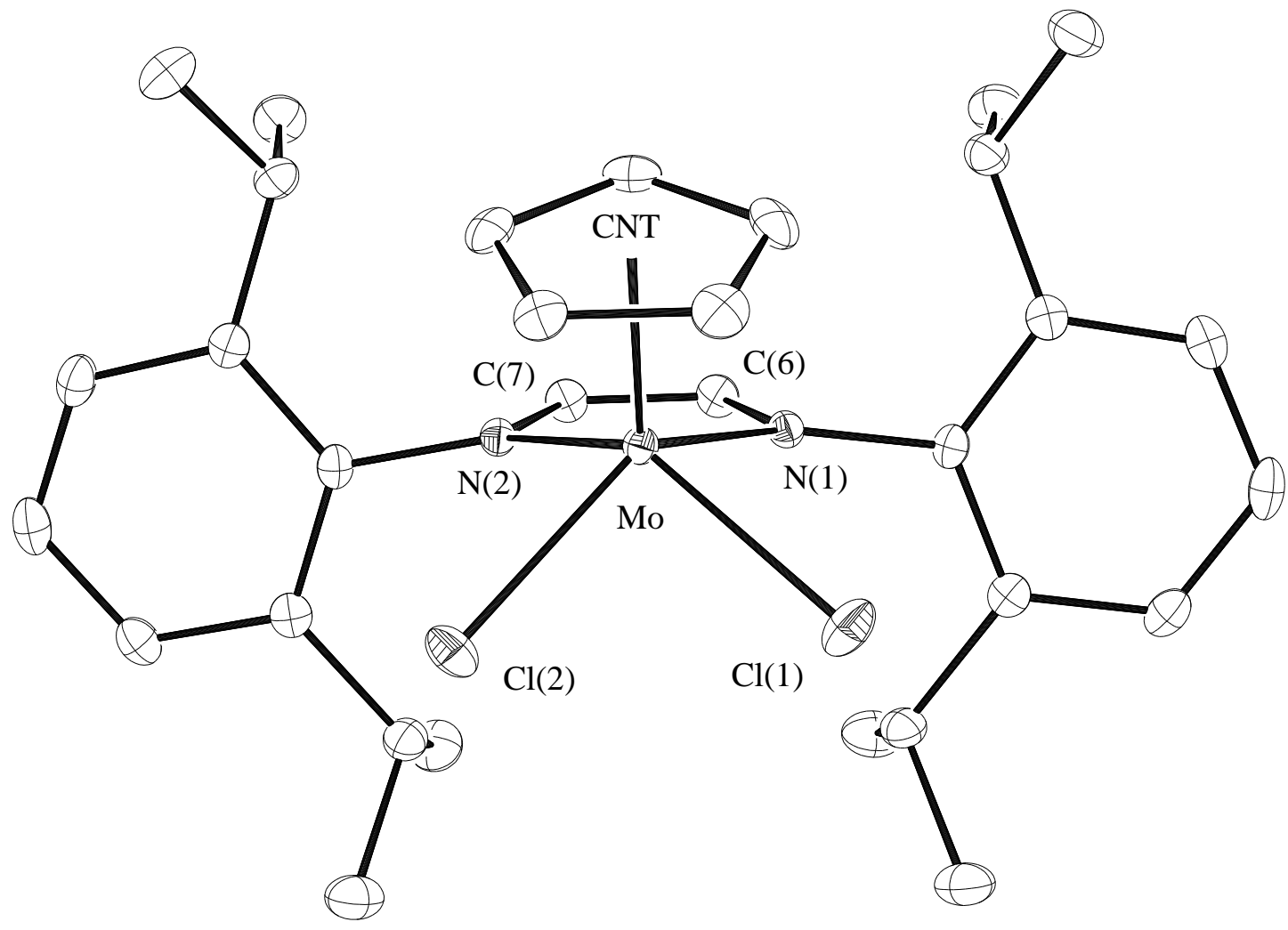


Figure 2

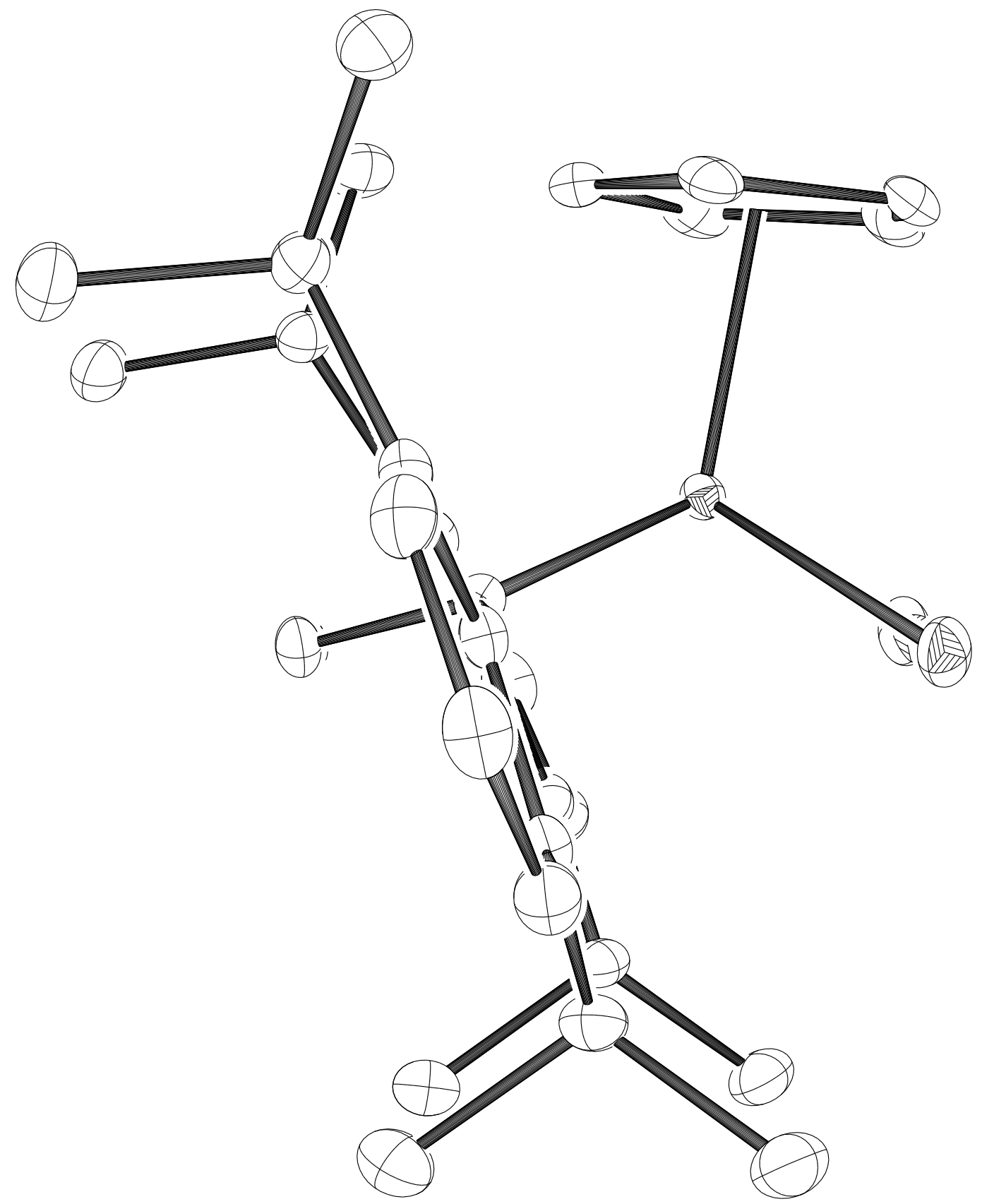


Figure 3

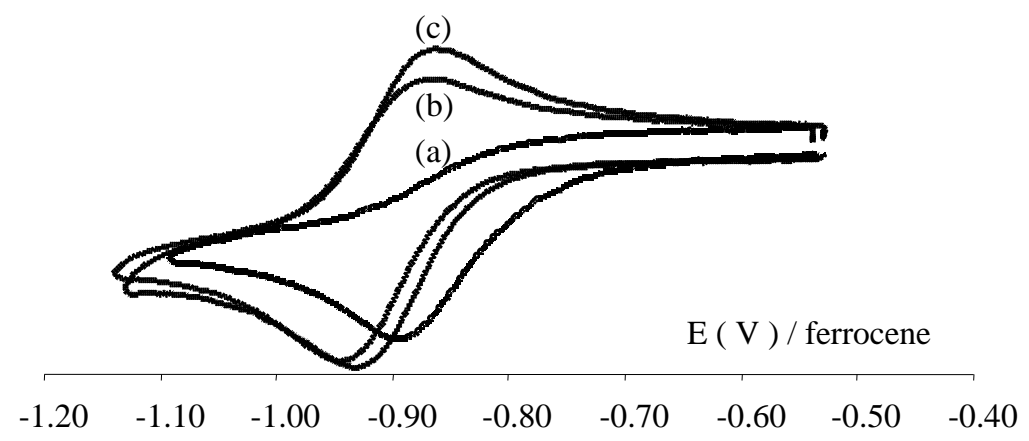

Figure 4

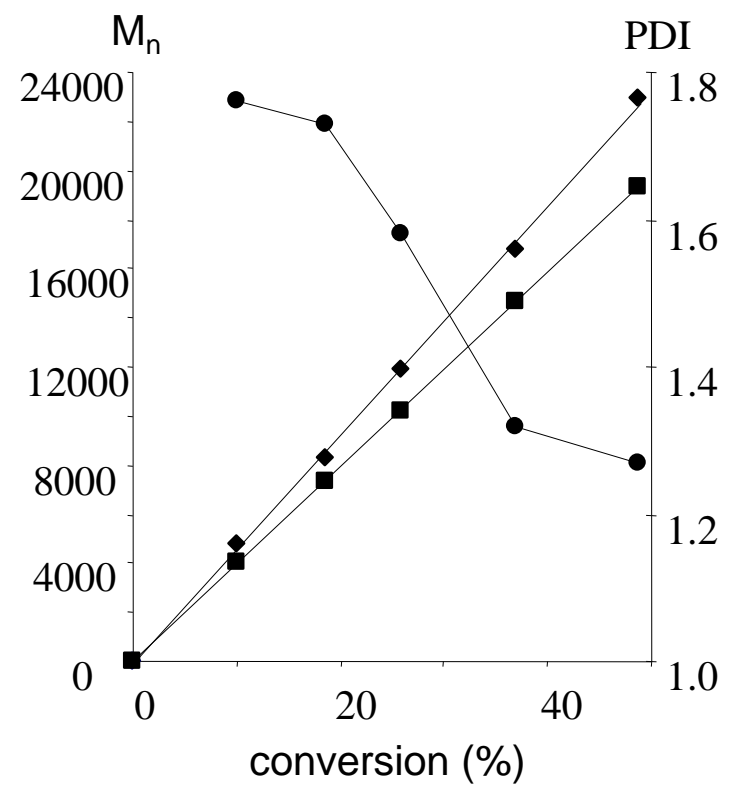


Figure 5

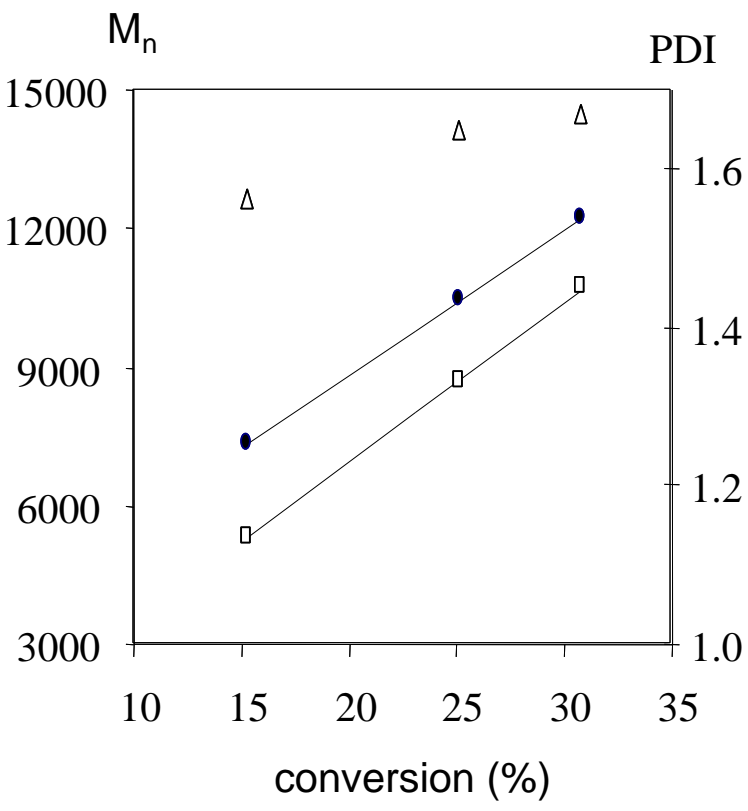


Scheme 1

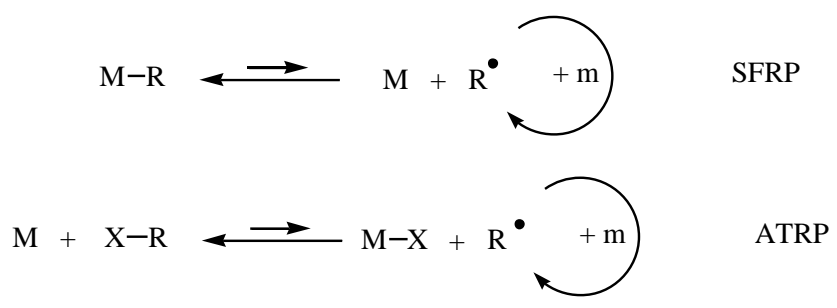

Scheme 2

$$
\begin{aligned}
& \mathrm{CpMoCl}_{2}\left(\mathrm{R}_{2} \text {-dad }\right) \underset{-\mathrm{e}^{-}}{\stackrel{+\mathrm{e}^{-}}{\rightleftarrows}}\left[\mathrm{CpMoCl}_{2}\left(\mathrm{R}_{2} \text {-dad }\right)\right]^{-} \\
& +\mathrm{Cl}^{-} \uparrow-\mathrm{Cl}^{-} \\
& \mathrm{CpMoCl}\left(\mathrm{R}_{2} \text {-dad }\right)
\end{aligned}
$$




\section{Equation 1}

$1 / 2\left[\mathrm{CpMoCl}_{2}\right]_{2}+\mathrm{R}-\mathrm{N} \prod_{\mathrm{N}-\mathrm{R}} \longrightarrow$

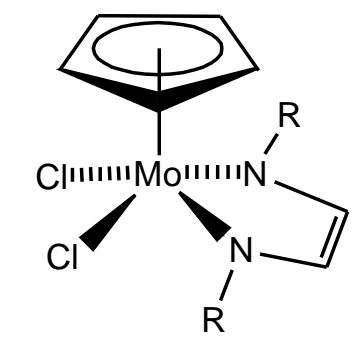

$$
\begin{aligned}
& \mathrm{R}=\mathrm{Ph} \quad 1 \\
& \text { p-Tol } 2 \\
& \mathrm{C}_{6} \mathrm{H}_{3} \operatorname{Pr}_{2}^{\mathrm{i}}{ }_{2,6} \quad 3 \\
& \mathrm{Pr}^{\mathrm{i}} 4
\end{aligned}
$$

\section{Equation 2}

$$
\mathrm{k}_{\mathrm{app}}=\mathrm{k}_{\mathrm{p}} \mathrm{K}_{\mathrm{ATRP}} \frac{[\mathrm{M}][\mathrm{R}-\mathrm{X}]}{[\mathrm{M}-\mathrm{X}]}
$$

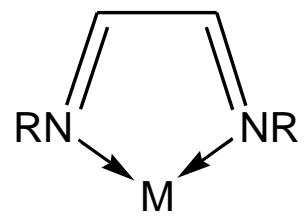

A

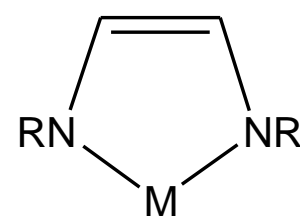

B

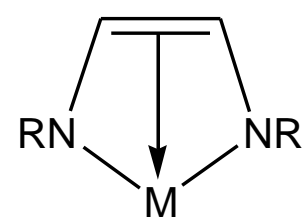

C 